Article

\title{
Preparation of Superhydrophobic Steel Surfaces with Chemical Stability and Corrosion
}

\author{
Chongwei Du ${ }^{1,2}$, Xiaoyan $\mathrm{He}^{1,2}$, Feng Tian ${ }^{1,2}$, Xiuqin Bai ${ }^{1,2, *}$ and Chengqing Yuan ${ }^{1,2}(\mathbb{D}$ \\ 1 Reliability Engineering Institute, National Engineering Research Center for Water Transport Safety, Wuhan \\ University of Technology, Wuhan 430063, China; cwd@whut.edu.cn (C.D.); hexiaoyan@whut.edu.cn (X.H.); \\ tianfeng221@whut.edu.cn (F.T.); ycq@whut.edu.cn (C.Y.) \\ 2 Key Laboratory of Marine Power Engineering and Technology, Ministry of Transport, Wuhan University of \\ Technology, Wuhan 430063, China \\ * Correspondence: xqbai@whut.edu.cn
}

Received: 25 May 2019; Accepted: 18 June 2019; Published: 20 June 2019

check for updates

\begin{abstract}
Corrosion seriously limits the long-term application of Q235 carbon steel. Herein, a simple fabrication method was used to fabricate superhydrophobic surfaces on Q235 carbon steel for anticorrosion application. The combination of structure and the grafted low-surface-energy material contributed to the formation of superhydrophobic steel surfaces, which exhibited a water contact angle of $161.6^{\circ}$ and a contact angle hysteresis of $0.8^{\circ}$. Meanwhile, the as-prepared superhydrophobic surface showed repellent toward different solutions with $\mathrm{pH}$ ranging from 1 to 14 , presenting excellent chemical stability. Moreover, the acid corrosive liquid ( $\mathrm{HCl}$ solution with $\mathrm{pH}$ of 1 ) maintained sphere-like shape on the as-prepared superhydrophobic surface at room temperature, indicating superior corrosion resistance. This work provides a simple method to fabricate superhydrophobic steel surfaces with chemical stability and corrosion resistance.
\end{abstract}

Keywords: carbon steel; chemical etching; superhydrophobic; chemical stability; corrosion resistance

\section{Introduction}

Q235 carbon steel, medium-low strength steel with low-cost, has a large number of applications in industrial fields, especially in marine environment [1]. However, Q235 carbon steel is prone to corrosion, especially in a neutral or acidic environment. The natural environment, including the atmosphere, water, and soil, is usually neutral or weakly acidic to induce serious corrosion of Q235 carbon steel [2,3]. In order to inhibit corrosion of Q235, various methods have been applied for improving anti-corrosion performance of Q235. Among them, cathodic protection and anti-corrosion coatings are widely used to prevent corrosion. However, the high cost and the consumption of non-ferrous metals limited the applications of cathodic protection technology. Anti-corrosion coatings could effectively isolate or inhibit the direct contact between the protected metals and the corrosive media by their shielding and resistance effect to slow the corrosion rate of the protected metal [4]. At present, there were various methods used to prepare anti-corrosion surfaces on metal substrates, including chemical etching [5], electrochemical deposition [6], anodizing [7], sol-gel [8], thermal oxidation [9], laser structuration [10], and thermal spraying [11]. The superhydrophobic surfaces have a very important position as a kind of anti-corrosion coating. The strong repellent ability against water of the superhydrophobic surface can greatly reduce the contact area of corrosive liquid and the surface, and hinder the migration of corrosive ions to metal materials, leading to a decrease in the corrosion rate of materials [12]. Chen et al. fabricated a superhydrophobic aluminum surface on steel substrate by suspension flame spraying in large-scale fabrication [13]. The superhydrophobic aluminum surface showed excellent anticorrosive performance with a contact angle of $151^{\circ}$. Xiang et al. prepared a superhydrophobic surface on mild 
steel. The fabrication process involved two steps, including formation of porous $\mathrm{ZnO}$ coatings and modification of myristic acid [14]. These studies were based on coatings to achieve superhydrophobicity. However, adhesion strength between the coatings and the substrate was a big problem which needs to be solved. Kietzig et al. fabricated dual scale roughness structures on different metals by femtosecond laser irradiation to achieve a hydrophobic surface with a contact angle above $150^{\circ}$ [10]. Jagdheesh et al. used a nanosecond laser light source on the stainless-steel plate to produce a single roughness micropattern. The as-prepared surface showed excellent superhydrophobicity with a roll-off angle of $5^{\circ}$ and a static contact angle of $180^{\circ}$ [15]. However, this method needs special equipment.

In our study, superhydrophobic surface on Q235 carbon steel was prepared by a two-step process, involving the formation of an irregular needle-like structure and fluorination treatment. The morphology of the needle-like microstructure was in-situ formed by chemical etching on carbon steel. The combination of structured surface and low surface material contributed to the formation of the superhydrophobic surface. The anti-wetting performance of the as-prepared superhydrophobic surface was further studied. The results demonstrated that the superhydrophobic surface exhibited a high water-contact angle $\left(\sim 161.6^{\circ}\right)$ and a low contact angle hysteresis $\left(\sim 0.8^{\circ}\right)$, suggesting the Cassie-Baxter state on the surface. Meanwhile, the bounce phenomenon of water droplets on the surface was photographed. More importantly, the as-prepared samples could maintain good hydrophobic properties toward the acid solution and base solution with pHs ranging from 1 to 14. The corrosion resistance to acid solution of the as-prepared superhydrophobic surface was also examined. The inspiring results might provide insight into developing superhydrophobic surfaces on iron substrates for enhanced performances.

\section{Materials and Methods}

\subsection{Materials}

The commercially available Q235 carbon steel (GB, containing element content: $\mathrm{Fe} \geq 98.675 \%$, C $0.14 \% \sim 0.22 \%$, Mn $0.30 \sim 0.65 \%, \mathrm{Si} \leq 0.210 \%, \mathrm{~S} \leq 0.200 \%, \mathrm{P} \leq 0.045 \%$ ) with a diameter of $10 \mathrm{~mm}$ and a thickness of $3 \mathrm{~mm}$ were used. $(1 \mathrm{H}, 1 \mathrm{H}, 2 \mathrm{H}, 2 \mathrm{H}$-perfluorodecyl)-triethoxysilane (PFTEOS, 97\%) was purchased from Aladdin Industrial Corporation (Shanghai, China). All chemicals were used as received without any further purification.

\subsection{Sample Preparation}

Q235 carbon steel discs were polished and washed by ethanol and deionized water, subsequently drying with flowing nitrogen. Q235 carbon steel discs were placed in Piranha solution at $35^{\circ} \mathrm{C}$ for $15 \mathrm{~min}$ and then washed by deionized water for three time. Piranha solution was prepared by mixing concentrated sulfuric acid $(95.0 \% \sim 98.0 \%, \mathrm{AR})$ and hydrogen peroxide $(30 \%, \mathrm{AR})$ in a volume ratio of 7:3. Finally, the treated steels were soaked in the $1 \%(v / v)$ ethanol solution of PFTEOS at $35^{\circ} \mathrm{C}$ for $24 \mathrm{~h}$, and then drying with nitrogen.

\subsection{Characterization}

To demonstrate the specific microstructure of the sample surface, a preliminary observation of the sample surface was performed using a field scanning electron microscope (FESEM, Zeiss Ultra Plus, Heidenheim, Germany). The roughness of samples was tested by a contourgraph (Huazhong University of Science and Technology, Wuhan, China). Analysis of the elemental composition of the sample surface was using energy-dispersive spectroscopy (EDS, Oxford, Abingdon, UK) at an accelerating voltage of $8 \mathrm{kV}$. Further analysis of the chemical composition of the sample was by X-ray photoelectron spectroscopy (XPS, ESCALAB 250Xi, Waltham, MA, USA) using Al-K $\alpha$ as the radiation source. The contact angle of the samples and controls were measured by a contact angle meter (Dataphysics OCA 15EC, Stuttgart, Germany). The contact angle of the sample toward acid solutions and base solutions was measured using a standard solution of $\mathrm{pH}$ ranging from 1 to 14 to 
evaluate the surface anti-wetting properties of the sample under acidic and alkaline conditions. The droplet size used to measure the water contact angle was $3 \mu \mathrm{L}$. Meanwhile, the bounce phenomenon of the droplet on the surface of the sample was observed and photographed with the droplet size of $5 \mu \mathrm{L}$. The contact angle hysteresis was calculated by adding and shrinking a small drop of deionized water (drop volume, $9 \mu \mathrm{L}$ ) on the surface. The image analysis system was used to digitally record and measure the advancing contact angle and the receding contact angle. The difference between advancing contact angle and the receding contact angle determined water contact angle hysteresis.

Electrochemical measurements were obtained in $3.5 \mathrm{wt} \% \mathrm{NaCl}$ solution by a CS300 electrochemical workstation with a standard three-electrode cell (CorrTest Instrument Co., Ltd., Wuhan, China). The saturated calomel electrode was used as the reference electrode. The platinum foil of $10 \times 10 \mathrm{~mm}^{2}$ surface area was used as a counter electrode. The working electrode with a circular exposed area of $0.785 \mathrm{~cm}^{2}$. Electrochemical impedance spectra were carried out with signals of $10 \mathrm{mV}$ amplitude in the frequency spectrum ranging from $100 \mathrm{kHz}$ to $0.01 \mathrm{~Hz}$. Potentiodynamic polarization curves were acquired with the potential range of $-200 \mathrm{mV}$ to $200 \mathrm{mV}$ versus $E_{\text {ocp }}$ at a scan rate of $1 \mathrm{mV} / \mathrm{s}$. The corrosion potential $\left(E_{\text {corr }}\right)$ and the corrosion current density $\left(I_{\text {corr }}\right)$ were calculated by CView 2.6.

\section{Results and Discussion}

Figure 1 showed the morphological features of the polished Q235 carbon steel and the structured Q235 carbon steel. The polished carbon steel was very smooth with an average roughness $\left(R_{\mathrm{a}}\right)$ of $39 \mathrm{~nm}$ (Figure 1a). The polished Q235 carbon steel substrates were immersed into the Piranha solution to obtain the structured surface. The addition of $\mathrm{H}_{2} \mathrm{O}_{2}$ in the acid solutions could accelerate the etching process and oxidation reactions [16]. The etching process of $\mathrm{H}_{2} \mathrm{O}_{2}$ and $\mathrm{H}_{2} \mathrm{SO}_{4}$ resulted in the microstructures on the Q235 carbon steel. The structured Q235 carbon steel exhibited a rough surface with complex and regular needle-like microstructures (Figure 1(b-1)). The needle-like microstructures were about $200 \mathrm{~nm}$ in length and $10 \mathrm{~nm}$ in width, resulting in nano-pores with diameter of $100 \mathrm{~nm}$. The roughness significantly increased to $491 \mathrm{~nm}$. The further grafting of PFTEOS on the structured Q235 carbon steel surface slightly reduced the roughness to $423 \mathrm{~nm}$. Moreover, the topography of the structured surface after modification of PFTEOS was similar with that of structured Q235 carbon steel surface (Figure 1c). The microstructures provided enough space to entrap air layer, which was an important factor to construct superhydrophobic surface.

The other factor that contributes to the surface wetting properties is the chemical compositions of the surface. The EDS results of polished Q235 carbon steel surface, structured Q235 carbon steel surface and structured surface after modification of PFTEOS were showed in Figure 2. The polished Q235 carbon steel surface only contained element Fe (Figure 2a). The structured Q235 carbon steel surface contained element $\mathrm{Fe}, \mathrm{O}$ and $\mathrm{C}$ (Figure 2b). It was obvious that the structured steel surface after modified PFTEOS consisted of elements Fe, F, and Si (Figure 2c), indicating that PFTEOS has been successfully grafted on the surface of the sample.

To further analyze the composition of structured surfaces before/after modified PFTEOS, XPS analyses of the surfaces were employed (Figure 3). The elemental compositions of the structured Q235 carbon steel surface was Fe, O, C (Figure 3(a-1)). While, the extra elements F and Si appeared on the structured steel surface after modification of PFTEOS, indicating that PFTEOS were successfully attached to the substrate surface after modification (Figure 3(b-1)). The O 1s spectra of the structured Q235 carbon steel surface resolved into two components, namely $\mathrm{C}-\mathrm{O}(530.98 \mathrm{eV})$ and $\mathrm{FeOOH}$ (529.68 eV) (Figure 3(a-2)), indicating that FeOOH can be formed on the surface of Q235 carbon steel after the chemically etched by Piranha solution. The $\mathrm{C} 1 \mathrm{~s}$ spectrum acquired from the structured Q235 carbon steel surface, was resolved into three components, namely C-C/C-H (284.60 eV), C-O $(286.10 \mathrm{eV})$ and $\mathrm{C}=\mathrm{O}(288.22 \mathrm{eV})$ [17] (Figure 3(a-3)). However, the spectra of the structured surface after modification of PFTEOS were different. The $\mathrm{O} 1 \mathrm{~s}$ spectra of the structured steel surface after modification of PFTEOS resolved into $\mathrm{C}=\mathrm{O}(532.60 \mathrm{eV})$ and $\mathrm{Fe}-\mathrm{O}-\mathrm{Si}(530.75 \mathrm{eV})$ (Figure 3(b-2)). The $\mathrm{C}$ 1 s spectrum was resolved into three components, namely C-C/C-H $(284.94 \mathrm{eV}), \mathrm{C}-\mathrm{O}(286.01 \mathrm{eV})$ and 
$\mathrm{C}=\mathrm{O}(288.24 \mathrm{eV}), \mathrm{CF}_{2}(291.62 \mathrm{eV})$ and $\mathrm{CF}_{3}(293.82 \mathrm{eV})$ [18] (Figure 3(b-3)). The $\mathrm{F} 1$ s proved the existence of C-F (689.02 eV) (Figure 3(b-4)). The XPS spectrum of Si 1s showed the formation of Si-O (103.09 eV) (Figure 3(b-5)). The $\mathrm{O} 1 \mathrm{~s}$ peak of $530.75 \mathrm{eV}$ of the modified Q235 carbon steel surface indicated the formation of $\mathrm{Fe}-\mathrm{O}-\mathrm{Si}$ bond by the chemical reaction of the organosilane and the hydroxylated aluminum surface (Figure 3(b-2)). The hydrolysis reaction between the silicon ethyoxyl $\left(\mathrm{Si}-\mathrm{OCH}_{2} \mathrm{CH}_{3}\right)$ of PFTEOS and the hydroxyl group in FeOOH on the surface was to form a self-assembled film by stable chemical binding. These results indicated that the PFTEOS was successfully chemical bonding to the carbon steel surface. As a result, the $\mathrm{CF}_{3}$ and $\mathrm{CF}_{2}$ groups were rich in the surface, which could improve the hydrophobic properties of Q235 carbon steel.



Figure 1. SEM images of polished Q235 carbon steel surface (a), structured Q235 carbon steel surface (b) and structured surface after modification of PFTEOS (c). (-2 is the high magnification image of -1 , respectively).
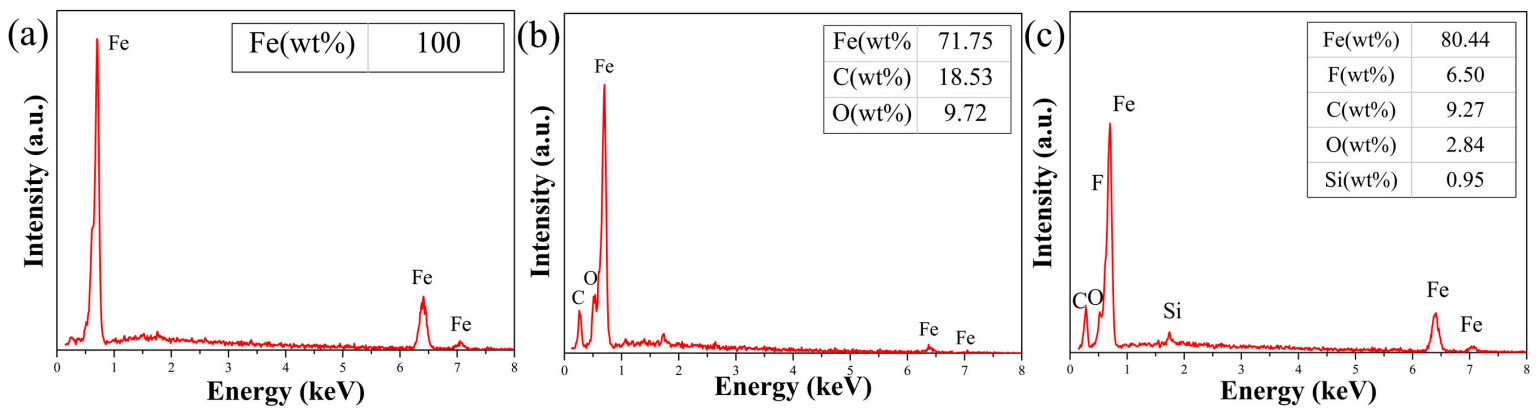

Figure 2. EDS of polished Q235 carbon steel surface (a), structured Q235 carbon steel surface (b), and structured surface after modification of PFTEOS (c). 

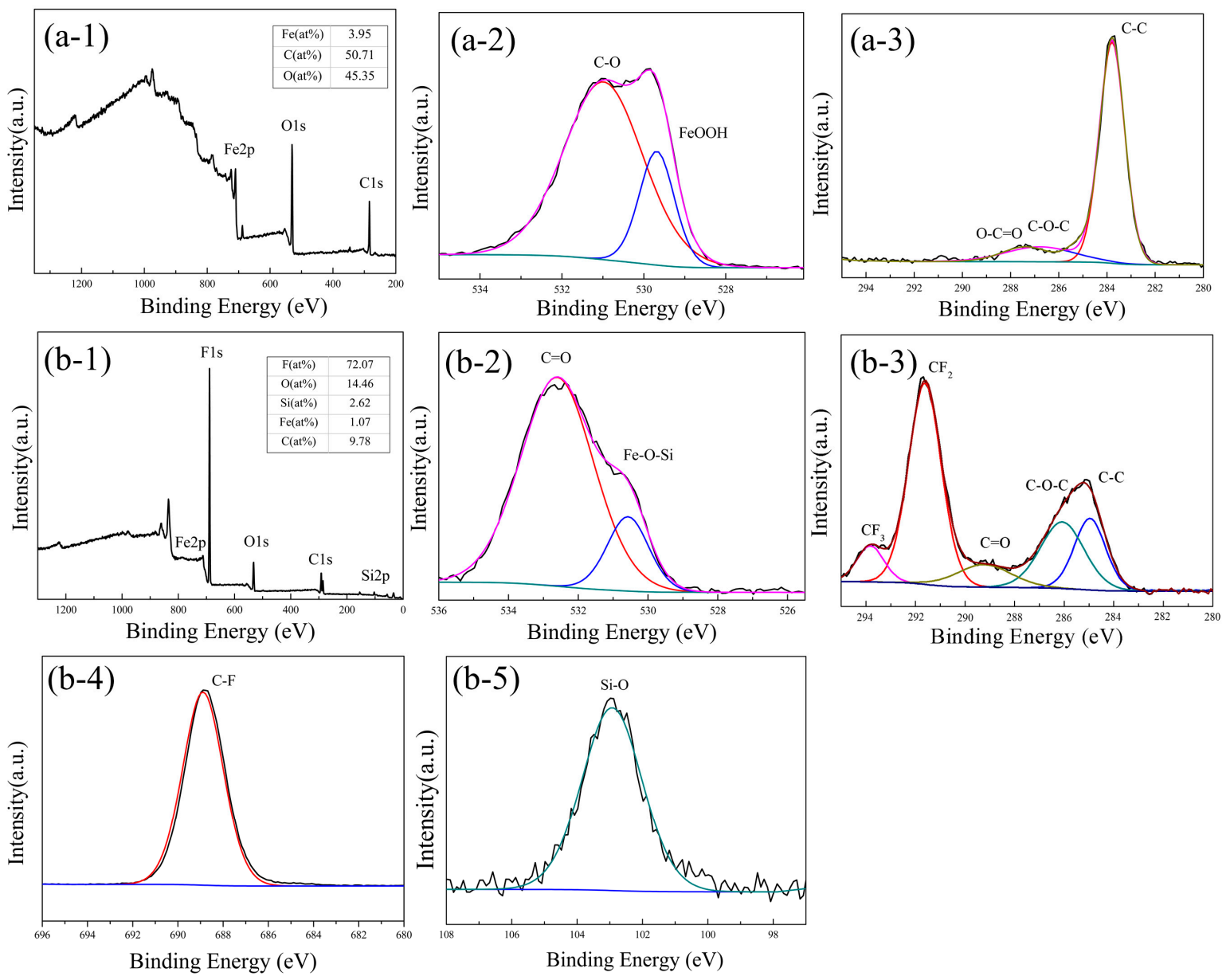

Figure 3. XPS spectra detected from structured Q235 carbon steel surface: the XPS survey spectra (a-1), $\mathrm{O} 1$ s spectra (a-2) and C 1 s spectra (a-3) and structured surface after modification of PFTEOS: the XPS survey spectra (b-1), O 1s spectra (b-2), C 1s spectra (b-3), F 1s spectra (b-4) and Si $2 p$ spectra (b-5). All spectra were corrected to the polluted $\mathrm{C} 1 \mathrm{~s}$ spectra.

Water contact angle (WCA) and contact angle hysteresis (CAH) were utilized to characterize the hydrophobic properties of the sample surfaces. The water contact angles of polished steel surface and the polished steel surface with grafted PFTEOS were $90.3^{\circ}$ and $99.1^{\circ}$, respectively (Figure $4 \mathrm{a}, \mathrm{b}$ ). WCA and CAH before and after PFTEOS modification were shown in Figure 4c,d. It could be clearly seen that the hydrophobic properties of the structured steel surface after modification of PFTEOS are much better than those of the structured Q235 carbon steel (Figure 4). The structured sample modified by PFTEOS has a WCA of $161.6^{\circ} \pm 0.5^{\circ}$ and a CAH of $0.8^{\circ} \pm 0.5^{\circ}$ (Figure $4 \mathrm{~d}$ ), which was a superhydrophobic surface. High WCA and low CAH indicated that the modified surface was in the Cassie-Baxter state. The surface of the structured surface is a rough surface with microstructure (Figure 4d), which provided enough space for the solid surface to lock the air and form an air layer. This air layer can effectively isolate the direct contact between the solid surface and the liquid to achieve hydrophobicity. According to the formula given by the Cassie-Baxter model definition [19], the percentage of solid surface area and gas-liquid area on the surface of the object can be calculated.

$$
\cos \theta_{\mathrm{r}}=f_{1} \cos \theta-f_{2}
$$

$\theta_{\mathrm{r}}$ : the contact angle on the structured surfaces after modification.

$\theta$ : the contact angle on the smooth surface after modification.

$f_{1}$ : The surface area of the liquid in contact with solid divided by the projected area. 
$f_{2}$ : The surface area of the liquid in contact with air divided by the projected area.

Water contact angle of polished surface after modification is $99.1^{\circ} \pm 0.5^{\circ}$ and the water contact angle of the structured surface after modification is $161.6^{\circ} \pm 0.5^{\circ}$. It is known that $f_{1}+f_{2}=1$. After calculation, $f_{1}$ is about $6.1 \%$, and $f_{2}$ is about $93.9 \%$. The contact area between the air and the liquid on the surface of the modified sample is much larger than the contact area between the solid and the liquid, which suggested that the superhydrophobic surface has been achieved. Therefore, the microstructure and the modification of PFTEOS contribute to the superhydrophobicity of Q235 carbon steel, resulting in an air layer to reduce the solid-liquid contact area.

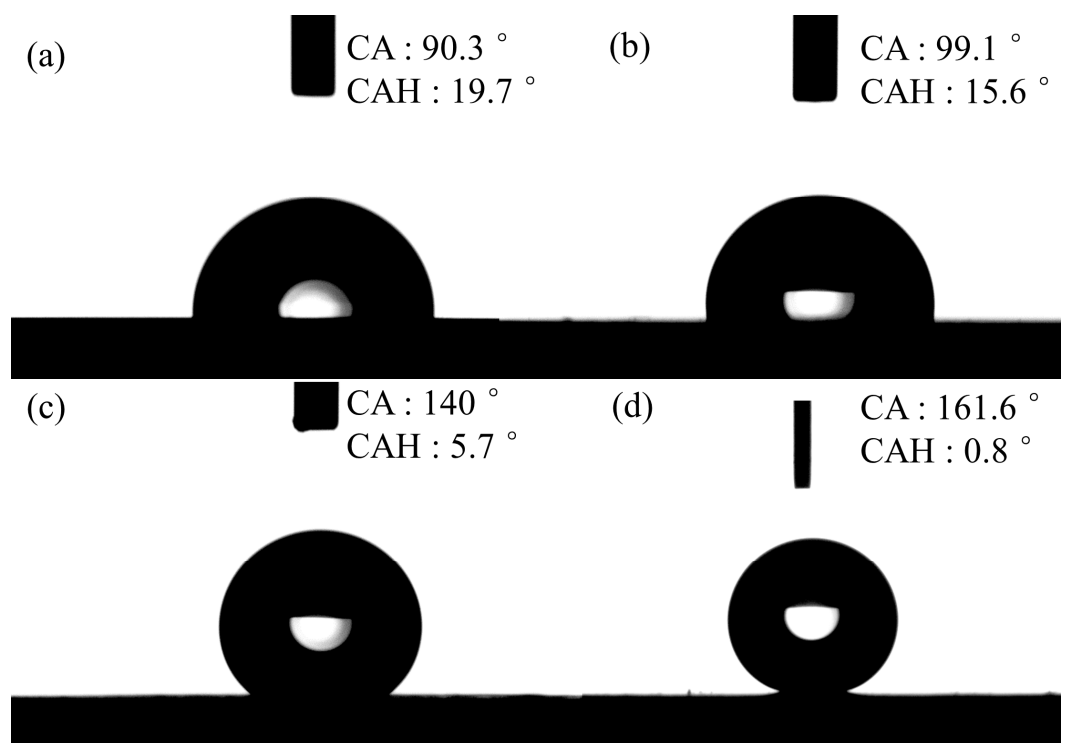

Figure 4. Contact angle of water on the polished Q235 carbon steel surface (a), polished steel surface after modification of PFTEOS (b), microstructured steel surface (c), and structured steel surface after modification of PFTEOS (d).

The bounce phenomenon of superhydrophobic Q235 carbon steel surface was showed in Figure 5. It took about $560 \mathrm{~ms}$ for the droplet to stay on the surface. The water droplet would compress, retract, and bounce off superhydrophobic Q235 carbon steel surface and the bounce phenomenon was repeated three times. As a result, the special wettability was highly similar with the surface of lotus leaf. This phenomenon further indicated that the superhydrophobic Q235 carbon steel surface was in Cassie-Baxter state with the extremely low water affinity.

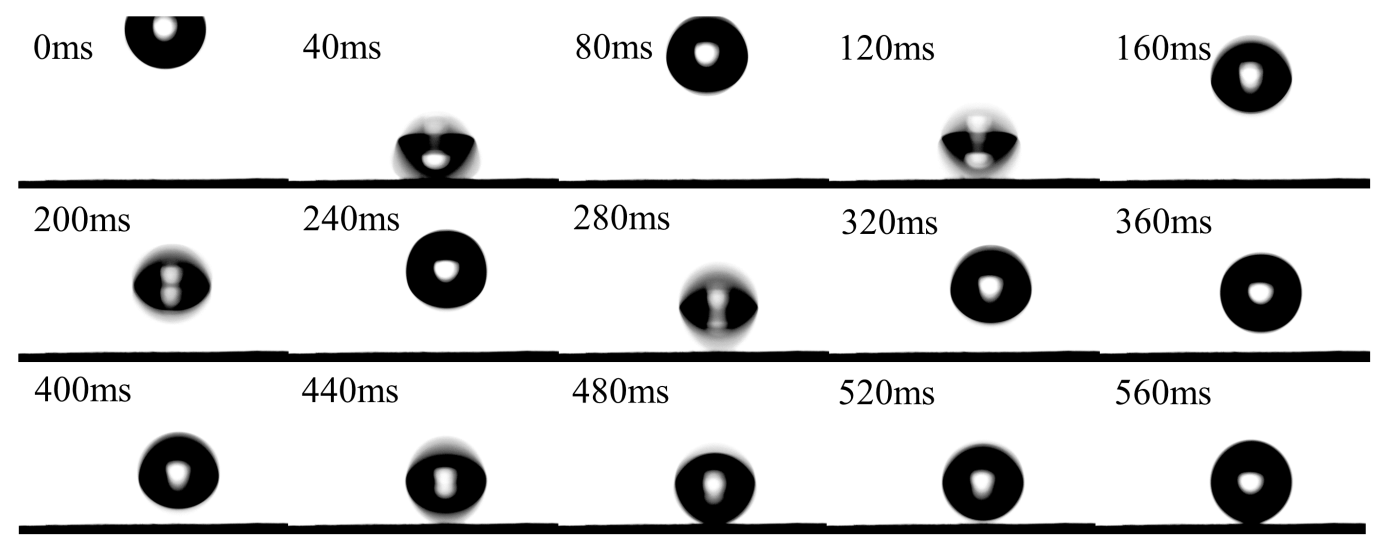

Figure 5. Bounce phenomenon of superhydrophobic Q235 carbon steel surface (5 $\mu \mathrm{L})$. 
The stability of superhydrophobic surfaces over a wide $\mathrm{pH}$-range is significant for practical applications in marine environment. Particularly, media with different $\mathrm{pH}$ values will impact performance of superhydrophobic surfaces. It was excited to note that the as-prepared superhydrophobic surfaces on Q235 carbon steel still maintained high hydrophobicity toward both acid and alkaline solutions (Figure 6), suggesting excellent chemical stability. However, the structured Q235 carbon steel could not maintain hydrophobicity toward acid solutions. The contact angles of both the structured Q235 carbon steel and the superhydrophobic Q235 carbon steel were stable when they were tested by the alkaline solutions. As we known, iron does not readily react with hydroxide ions at room temperature, so alkaline solutions had no influence on their wettability. The acid solutions significantly influenced the wettability of the structured Q235 carbon steel with an obvious decrease to $74.2^{\circ}$. While, the as-prepared superhydrophobic surfaces on Q235 carbon steel still maintained high hydrophobicity toward acid solution with a $\mathrm{pH}$ of 1 .

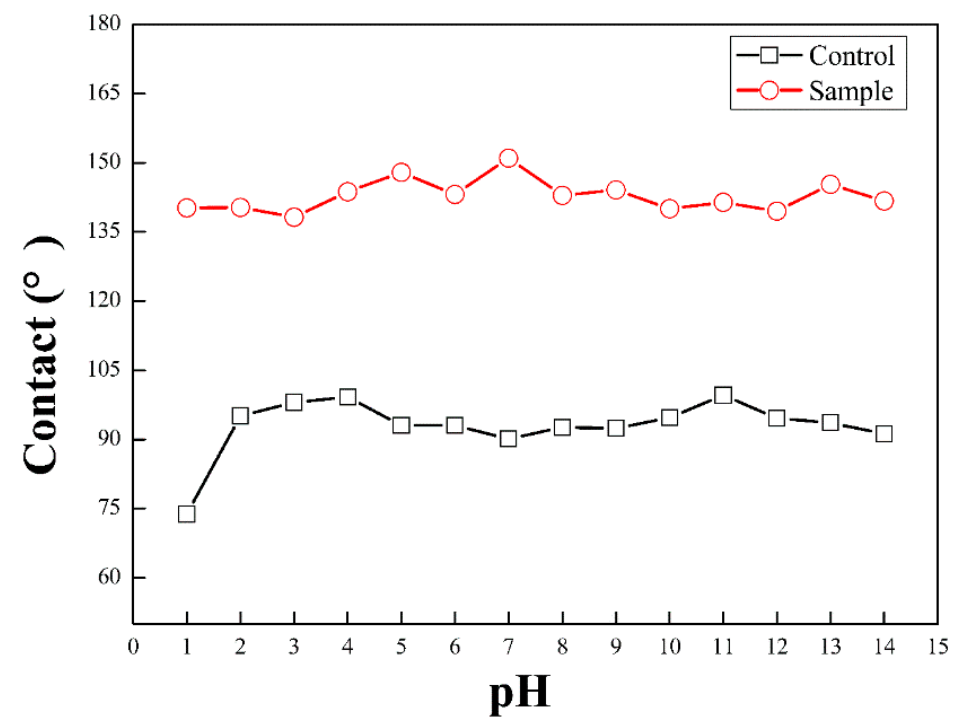

Figure 6. Comparison of different $\mathrm{pH}$ environments contact angle of structured Q235 carbon steel and superhydrophobic Q235 carbon steel.

To evaluate the corrosion resistance of the superhydrophobic surface, the EIS and potentiodynamic polarization curves were performed. EIS analyses were used to assess their corrosion resistances and the Nyquist plots were shown in Figure 7a. The impedance of superhydrophobic Q235 carbon steel is much higher than those of the untreated Q235 carbon steel and structured Q235 carbon steel, indicating that the corrosion resistance of superhydrophobic samples is better than the other samples [20]. The potentiodynamic polarization results were consistent with the results obtained from EIS. The potentiodynamic polarization results were shown in Figure $7 \mathrm{~b}$. In the polarization curves, the lower $I_{\text {corr }}$ and higher $E_{\text {corr }}$ indicates the higher corrosion resistance [21]. The $I_{\text {corr }}$ of the superhydrophobic Q235 carbon steel is about $0.577 \mu \mathrm{A} / \mathrm{cm}^{2}$, which is much lower than those of the untreated Q235 carbon steel $\left(6.601 \mu \mathrm{A} / \mathrm{cm}^{2}\right)$ and structured Q235 carbon steel $\left(3.917 \mu \mathrm{A} / \mathrm{cm}^{2}\right)$. Meanwhile, the $E_{\text {corr }}$ of the superhydrophobic Q235 carbon steel is positive-shifting comparing with the other samples. The results suggest that the superhydrophobic Q235 carbon steel samples exhibit excellent corrosion resistance.

To visually exhibit the superhydrophobicity and anticorrosion performance of the superhydrophobic Q235 carbon steel, a highly corrosive liquid droplet $\left(\mathrm{pH}=1 \mathrm{HCl}+\mathrm{CuSO}_{4}\right)$ was dropped onto the untreated Q235 carbon steel, structured Q235 carbon steel, superhydrophobic Q235 carbon steel (Figure 8). It could be seen that the untreated Q235 carbon steel began to corrode at $10 \mathrm{~s}$ and the corrosion area gradually increased in the $60 \mathrm{~s}$ (Figure 8a). The structured samples had a certain corrosion resistance. The damage of the structured Q235 carbon steel occurred after contact with the corrosive liquid droplet for $7 \mathrm{~min}$. The ball-like shape of the droplets was not be maintained, and the color of the 
corrosive liquid droplets turned to reddish brown, indicating the formation of ferric ions (Figure 8b). The oxidation film on the structured Q235 carbon steel caused by the $\mathrm{H}_{2} \mathrm{O}_{2}$ in $\mathrm{H}_{2} \mathrm{SO}_{4}$ solution could have contributed to the corrosion resistance [22]. Therefore, the structured Q235 carbon steel had better anticorrosion performance than the untreated Q235 carbon steel. However, the droplets of the highly-corrosive liquid solution on the superhydrophobic Q235 carbon steel retained their sphere-like shape for at least $10 \mathrm{~min}$ (Figure 8c). The results demonstrated that the superhydrophobic Q235 carbon steel was greatly stable toward acid solutions. The air layer captured on the superhydrophobic Q235 carbon steel could isolate the corrosive liquid droplet and the substrate to obtain corrosion resistance.
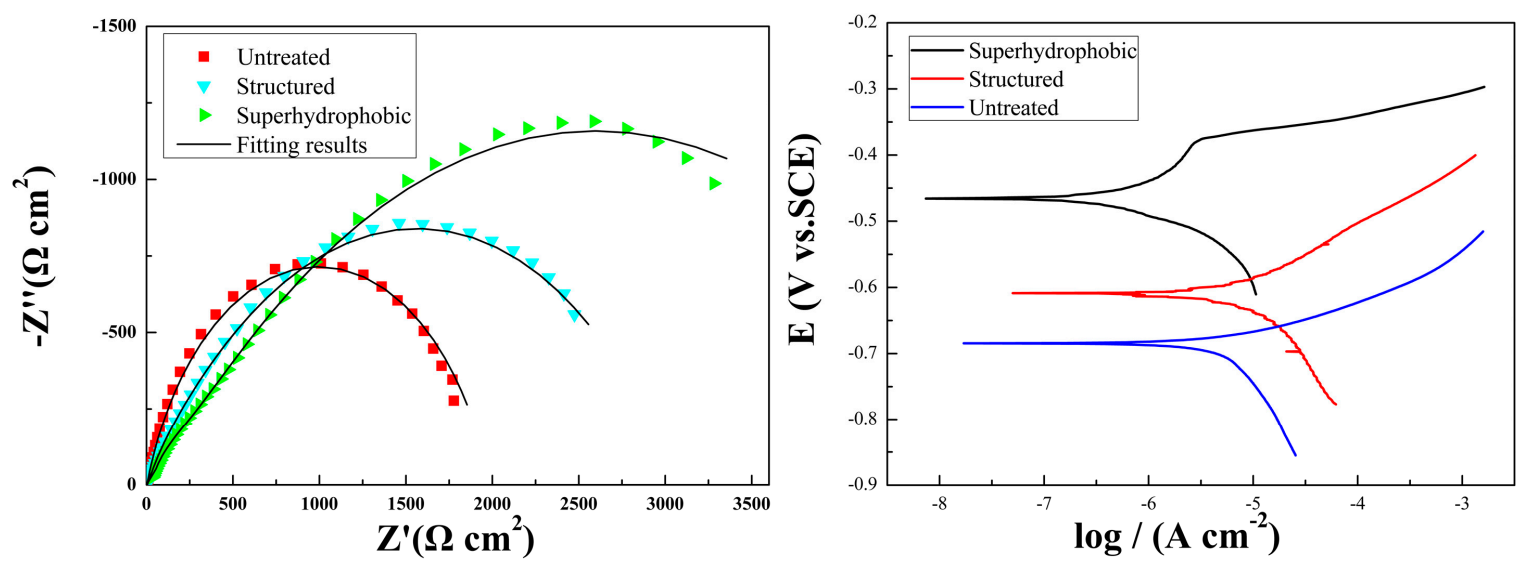

Figure 7. Nyquist plots (a) and Potentiodynamic polarization curves (b) of untreated Q235 carbon steel samples, structured Q235 carbon steel samples, and superhydrophobic Q235 carbon steel samples.

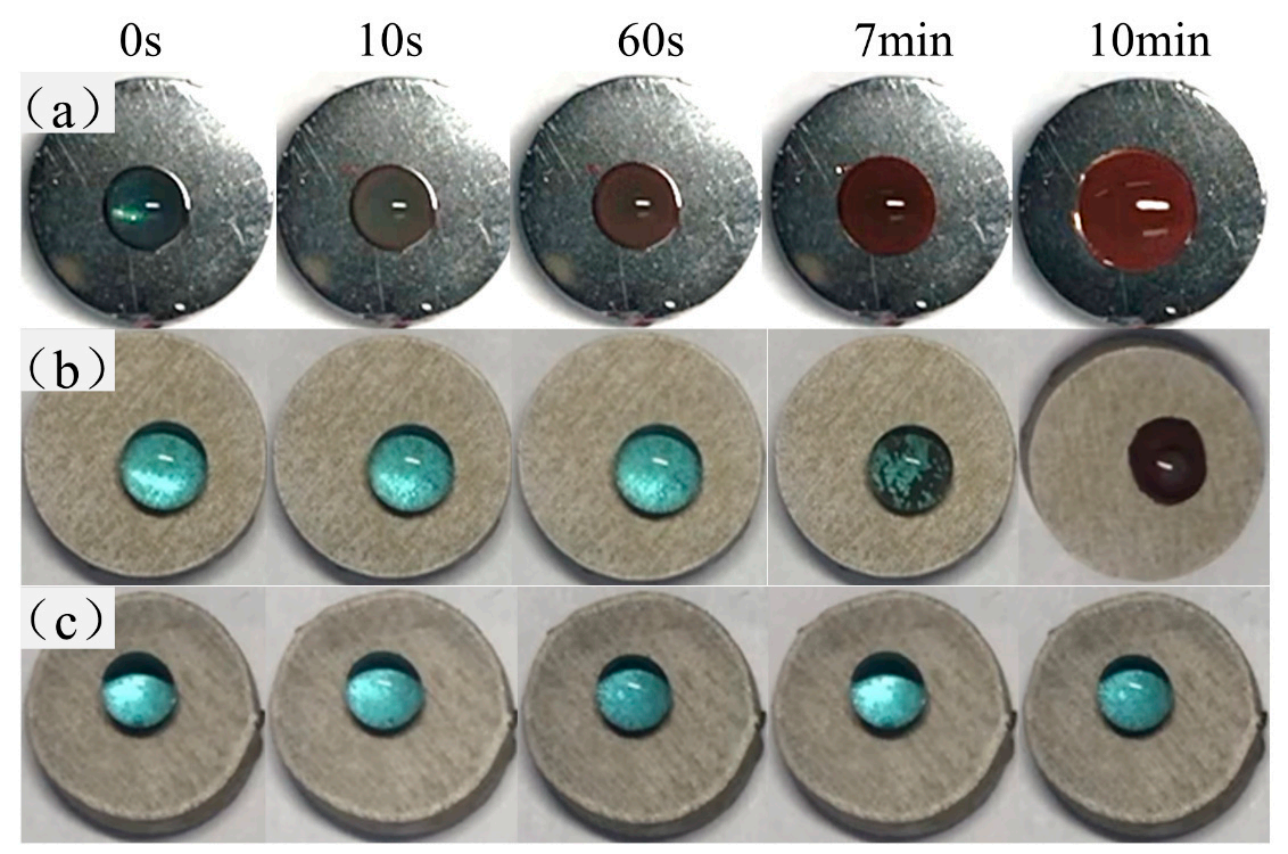

Figure 8. Sequential images of a highly corrosive liquid droplet $\left(\mathrm{pH}=1 \mathrm{HCl}+\mathrm{CuSO}_{4}\right)$ on the surfaces of untreated Q235 carbon steel (a), structured Q235 carbon steel (b), superhydrophobic Q235 carbon steel (c).

\section{Conclusions}

Our study proposed a simple and efficient to fabricate superhydrophobic surface on Q235 carbon steel. The surface of Q235 carbon steel was chemically etched by Piranha solution to produce FeOOH with microstructure and then PFTEOS could graft onto the surface by covalent bonding with $\mathrm{FeOOH}$. 
The microstructure and modification of PFTEOS resulted in superhydrophobic surface on Q235 carbon steel. The as-prepared surface could show repellent toward water, acid solutions, and alkaline solutions. Meanwhile, the superhydrophobic surface on Q235 carbon steel was in Cassie-Baxter state, which the existed air layer could isolated solid-liquid interface to inhibit corrosion. This provides a reference for future research on steel corrosion protection.

Author Contributions: C.D. carried out the literature search, figures, data collection, data analysis, data interpretation and writing. X.H., F.T. and X.B. conceived for study design. X.H. and F.T. participated in data collection. X.H., F.T., X.B. and C.Y. contributed to data analysis. X.H., X.B. and C.Y. were responsible for writing and revision.

Funding: This work was supported by China Postdoctoral Science Foundation (Grant No. 2017M622542), and Hubei Postdoctoral Sustentation Foundation, China (Grant No. G22).

Acknowledgments: The authors would like to thank the supporting by the Material research and testing center (Wuhan university of technology).

Conflicts of Interest: The authors declare no conflict of interest.

\section{References}

1. Usher, K.M.; Kaksonen, A.H.; Cole, I.; Marney, D. Critical review: Microbially influenced corrosion of buried carbon steel pipes. Int. Biodeterior. Biodegrad. 2014, 93, 84-106. [CrossRef]

2. Strickland, D.M. The resistivity of iron and its application to the chemical industry. Ind. Eng. Chem. 1923, 15, 566-569. [CrossRef]

3. Guo, W.; Chen, S.; Feng, Y.; Yang, C. Investigations of triphenyl phosphate and Bis-(2-ethylhexyl) phosphate self-assembled films on iron surface using electrochemical methods, fourier transform infrared spectroscopy, and molecular simulations. J. Phys. Chem. C 2007, 111, 3109-3115. [CrossRef]

4. Pu, N.W.; Shi, G.N.; Liu, Y.M.; Sun, X.; Chang, J.K.; Sun, C.L.; Ger, M.-D.; Chen, C.Y.; Wang, P.C.; Peng, Y.Y.; et al. Graphene grown on stainless steel as a high-performance and ecofriendly anti-corrosion coating for polymer electrolyte membrane fuel cell bipolar plates. J. Power Sources 2015, 282, 248-256. [CrossRef]

5. Huang, Y.; Sarkar, D.; Chen, X.-G. Fabrication of corrosion resistance micro-nanostructured superhydrophobic anodized aluminum in a one-step electrodeposition process. Metals 2016, 6, 47. [CrossRef]

6. Zhao, G.; Xue, Y.; Huang, Y.; Ye, Y.; Walsh, F.C.; Chen, J.; Wang, S. One-step electrodeposition of a self-cleaning and corrosion resistant $\mathrm{Ni} / \mathrm{WS}_{2}$ superhydrophobic surface. RSC Adv. 2016, 6, 59104-59112. [CrossRef]

7. Liang, J.; Liu, K.; Wang, D.; Li, H.; Li, P.; Li, S.; Su, S.; Xu, S.; Luo, Y. Facile fabrication of superhydrophilic/ superhydrophobic surface on titanium substrate by single-step anodization and fluorination. Appl. Surf. Sci. 2015, 338, 126-136.

8. Yang, H.; Pi, P.; Cai, Z.Q.; Wen, X.; Wang, X.; Cheng, J.; Yang, Z.R. Facile preparation of super-hydrophobic and super-oleophilic silica film on stainless steel mesh via sol-gel process. Appl. Surf. Sci. 2010, 256, 4095-4102. [CrossRef]

9. Zhang, F.; Zhang, C.; Song, L.; Zeng, R.; Li, S.; Cui, H. Fabrication of the superhydrophobic surface on magnesium alloy and its corrosion resistance. J. Mater. Sci. Technol. 2015, 31, 1139-1143. [CrossRef]

10. Kietzig, A.M.; Hatzikiriakos, S.G.; Englezos, P. Patterned superhydrophobic metallic surfaces. Langmuir 2009, 25, 4821-4827. [CrossRef]

11. Men, X.; Zhang, Z.; Yang, J.; Zhu, X.; Wang, K.; Jiang, W. Spray-coated superhydrophobic coatings with regenerability. New J. Chem. 2011, 35, 881-886. [CrossRef]

12. He, G.; Lu, S.; Xu, W.; Yu, J.; Wu, B.; Cui, S. Fabrication of durable superhydrophobic electrodeposited tin surfaces with tremella-like structure on copper substrate. Surf. Coatings Technol. 2017, 309, 590-599. [CrossRef]

13. Chen, X.; Yuan, J.; Huang, J.; Ren, K.; Liu, Y.; Lu, S.; Li, H. Large-scale fabrication of superhydrophobic polyurethane/nano- $\mathrm{Al}_{2} \mathrm{O}_{3}$ coatings by suspension flame spraying for anti-corrosion applications. Appl. Surf. Sci. 2014, 311, 864-869. [CrossRef]

14. Xiang, T.; Han, Y.; Guo, Z.; Wang, R.; Zheng, S.; Li, S.; Li, C.; Dai, X. Fabrication of inherent anticorrosion superhydrophobic surfaces on metals. ACS Sustain. Chem. Eng. 2018, 6, 5598-5606. [CrossRef] 
15. Jagdheesh, R.; Diaz, M.; Marimuthu, S.; Ocana, J.L. Robust fabrication of $\mu$-patterns with tunable and durable wetting properties: hydrophilic to ultrahydrophobic via a vacuum process. J. Mater. Chem. A 2017, 5, 7125-7136. [CrossRef]

16. Tsujino, K.; Matsumura, M. Morphology of nanoholes formed in silicon by wet etching in solutions containing $\mathrm{HF}$ and $\mathrm{H}_{2} \mathrm{O}_{2}$ at different concentrations using silver nanoparticles as catalysts. Electrochim. Acta 2007, 53, 28-34. [CrossRef]

17. Olivares, O.; Likhanova, N.V.; Gómez, B.; Navarrete, J.; Llanos-Serrano, M.E.; Arce, E.; Hallen, J.M. Electrochemical and XPS studies of decylamides of $\alpha$-amino acids adsorption on carbon steel in acidic environment. Appl. Surf. Sci. 2006, 252, 2894-2909. [CrossRef]

18. Vandencasteele, N.; Reniers, F. Plasma-modified polymer surfaces: Characterization using XPS. J. Electron Spectros. Relat. Phenomena 2010, 178-179, 394-408. [CrossRef]

19. Parry, V.; Berthomé, G.; Joud, J.C. Wetting properties of gas diffusion layers: Application of the Cassie-Baxter and Wenzel equations. Appl. Surf. Sci. 2012, 258, 5619-5627. [CrossRef]

20. Xue, Y.; Wang, S.; Zhao, G.; Taleb, A.; Jin, Y. Fabrication of Ni-Co coating by electrochemical deposition with high super-hydrophobic properties for corrosion protection. Surf. Coatings Technol. 2019, 363, 352-361. [CrossRef]

21. Chellouli, M.; Chebabe, D.; Dermaj, A.; Erramli, H.; Bettach, N.; Hajjaji, N.; Casaletto, M.P.; Cirrincione, C.; Privitera, A.; Srhiri, A. Corrosion inhibition of iron in acidic solution by a green formulation derived from Nigella sativa L. Electrochim. Acta 2016, 204, 50-59. [CrossRef]

22. Homjabok, W.; Permpoon, S.; Lothongkum, G. Pickling behavior of AISI 304 stainless steel in sulfuric and hydrochloric acid solutions. J. Met. Mater. Miner. 2017, 20, 1-6.

(C) 2019 by the authors. Licensee MDPI, Basel, Switzerland. This article is an open access article distributed under the terms and conditions of the Creative Commons Attribution (CC BY) license (http://creativecommons.org/licenses/by/4.0/). 